Original Research Paper

\title{
Trend and Pattern in Average Monthly Maximum Temperatures in Thailand from 1986 to 2015
}

\author{
Manachai Rodchuen, Samruam Chongcharoen and Walaithip Bunyatisai \\ Department of Statistics, Faculty of Science, Chiang Mai University, Chiang Mai 50200, Thailand
}

\author{
Article history \\ Received: 27-01-2020 \\ Revised: 03-03-2020 \\ Accepted: 24-03-2020 \\ Corresponding Author: \\ Walaithip Bunyatisai \\ Department of Statistics, \\ Faculty of Science, Chiang Mai \\ University, Chiang Mai 50200, \\ Thailand \\ Email: walaithip.bun@gmail.com
}

\begin{abstract}
This research aims to study the trends and patterns of average maximum temperature change data of monthly surface in Thailand during the 30 year-period from 1986 to 2015 that has already eliminated seasonal variations and autocorrelation. The data set obtained from Climatological center, Meteorological Development Division, Thailand Meteorological Department for 73 completed recording stations. The climatically regions of Thailand meteorology are divided into 5 regions: Central, Eastern, North, Northeast and South. After the process of parameter estimation using simple linear regression of average maximum temperature data that has already eliminated influences of variations, the study results showed that over the last 10 years, the northern, central, eastern, northeastern and southern regions of Thailand had trends of the average maximum surface temperature increasing by $0.164^{\circ} \mathrm{C} 0.137^{\circ} \mathrm{C} 0.127^{\circ} \mathrm{C} 0.194^{\circ} \mathrm{C}$ $0.068^{\circ} \mathrm{C}$, respectively. For over the whole country, the average maximum surface temperature increasing by $0.141^{\circ} \mathrm{C}$ in the last 10 years at a significant level of 0.05 .
\end{abstract}

Keywords: Seasonal Effect, Autoregressive Process, Maximum Temperatures, Linear Regression Model, Thailand

\section{Introduction}

Global warming, a crucial environmental problem, is one of the most important issue in the world today. This warming is associated with shifting rainfall pattern, rising sea level, melting of snow and iceberg and the frequency and intensity of extreme events such as heavy precipitation events, drought, wildfires, severe storms (IPCC, 2001; Hughes, 2003; IPCC, 2007; CCSP, 2008; ADB, 2009). Therefore, the warming can affect a range of natural and human activities, including agriculture (Schlenker and Roberts, 2009; Smith et al., 2009), health (Dhimal et al., 2015; Xu et al., 2015), the environment (Jones et al., 1999; Johannessen et al., 2004) and energy consumption (Paniagua-Tineo et al., 2011; Jaglom et al., 2014); it affects every sphere of human life (GuphaSapir et al., 2004; IPCC, 2007; Sharma et al., 2018). The world has been confronted with the consequences of global warming both at a global and regional scale (IPCC, 2012).

An analysis of observational records shows that the global surface temperature has increased since 1861 (Jones et al., 1999), furthermore, temperature rise is not reflected equally in every part of the planet. For example, using annual mean, Jones et al. (1999) showed that annual global surface temperatures warmed by $0.57^{\circ} \mathrm{C}$ over the period $1861-1997$ and by $0.37^{\circ} \mathrm{C}$ over the period $1925-1944$, the 20 -year period of the greatest warming. Over both periods the warming was slightly greater in the southern hemispheres than in the northern hemispheres. Hansen et al. (2006) also found that the annual mean global surface temperature has increased approximately $0.2^{\circ} \mathrm{C}$ per decade in the 30-year period, 1975-2005. IPCC (2001) and Turner et al. $(2002 ; 2005)$ have reported an increase in mean air surface temperatures in the Antarctic region (IPCC, 2001; Turner et al., 2002; 2005). Overpeck et al. (1997) revealed that the average Arctic temperature increased about $0.6^{\circ} \mathrm{C}$ from the beginning of the 20th century, whereas the maximum temperatures there have increased approximately $1.2^{\circ} \mathrm{C}$ since 1945 . Collins et al. (2000) determined trends in annual frequencies of extreme temperature events on the continent of Australia. The results show that the occurrences of warm events have generally increased over the period 1957-1996, while the number of cool extremes has decreased. McAlpine et al. (2007) found a statistically significant warming of 
mean annual temperature $\left(0.1-0.6^{\circ} \mathrm{C}\right)$ for the period 1951-2003 in eastern and northeast Australia and in southwest Western Australia. According to the study by Chooprateep and McNeil (2014) studied the monthly seasonally-adjusted surface temperature patterns in Southeast Asia from 1973 to 2008. The results show that temperatures have increased in all regions, with the increases ranging from 0.091 to $0.240^{\circ} \mathrm{C}$ per decade.

In recent decades, many studies have examined possible trends and patterns of temperature changes over the Earth's surface using several methodologies, including simulation models (Johannessen et al., 2004), empirical orthogonal functions (Semenov, 2007), remote sensing algorithms (Li et al., 2013) and various statistical techniques such as multiple linear regression (Lean and Rind, 2009), linear regression analysis, Pearson correlation analysis (Houghton and Tourre, 1992; Mote, 2003; Griffiths et al., 2005), multiple regression model with non-Gaussian correlated errors and linear Autoregressive Moving Average (ARMA) models (Hughes et al., 2006), Ordinary Least Squares (OLS) regression, DurbinWatson statistic (Collins, 2011), polynomial regression model (Wanishsakpong and McNeil, 2016), combination of cubic spline function and polynomial regression model (Sharma et al., 2018), multivariate linear regression, linear spline functions and factor analysis (Chooprateep and McNeil, 2014), time series analysis, linear regression and factor analysis (Wanishsakpong et al., 2016), Mann-Whitney U test (James and Washington, 2013), Mann-Kendall test (Klein Tank et al., 2006; Collins, 2011; Tshiala et al., 2011), the $r$ largest order statistics approach (Nemukula and Sigauke, 2018), cluster analysis (Mahlstein and Knutti, 2009), principal component analysis (Houghton and Tourre, 1992; Jones et al., 1999), principal component and hierarchical cluster analysis using the Ward method (Rebetez and Reinhard, 2007) and T-mode principal component analysis by convergent K-mean clustering (Jiang et al., 2012), time series analysis, linear regression and factor analysis for classification of the trends and patterns of temperature change (Wanishsakpong et al., 2016).

Thailand is already experiencing the impacts of temperature change. Thailand's Department of Meteorology reported that the annual mean temperature in Thailand rose by approximately one-degree celsius from 1981 to 2007 (Marks, 2011). According to models developed locally, the mean daily maximum temperature in Thailand will increase by 1.2 to $1.9^{\circ} \mathrm{C}$ by 2050 (The World Bank, 2009). Based on the Climate Risk Index (CRI) developed by Eckstein et al. (2018) Thailand has been ranked as one of the country's most vulnerable to climate change impacts, due to its highly dependence on climate-sensitive sectors such as natural and water resources, agriculture and fisheries for socioeconomic development and local livelihoods (Weiss, 2009; Mark, 2011). Therefore, analyzing and searching for evidence of any changes in climate are becoming very important for the region (Limsakul et al., 2011).

In this study, the trends and patterns of maximum temperature changes data of monthly surface in Thailand in a period of year 1986 to 2015 (30 years) have been examined, based on monthly temperature data. Because major climate-induced changes could have severe negative impacts on Thai food production, particularly rice. This knowledge will improve our understanding and provide scientific information for further vulnerability in different regions of Thailand. This information can also help the Thai government to make management plans such as water management, refugee settlement, energy policy and others.

\section{Materials and Methods}

\section{Data Management and Study Areas}

Thailand, the middle of mainland Southeast Asia, is located in the tropical area between latitude $5^{\circ} 37^{\prime}$ north to $20^{\circ} 27^{\prime}$ north and between longitude $97^{\circ} 22^{\prime}$ east to $105^{\circ} 37^{\prime}$ east. The estimated total area is $513,115 \mathrm{~km} 2$. In this research, the study area covered between latitude $5^{\circ}$ to $21^{\circ}$ north and longitude at $97^{\circ}$ to $106^{\circ}$ east of Thailand. According to the climate pattern and meteorological conditions, Thailand is divided into 5 climatic regions and the topography of each region is quite different as shown in Fig. 1.

The average monthly maximum temperature data were obtained from Climatological center, Meteorological Development Division, Thai Meteorological Department, consisting of 121 meteorological stations. Out of 121 meteorological stations, only 73 meteorological stations during the 30 year-period from 1986 to 2015 have complete temperature recording data as we need. Therefore, temperature data from these 73 meteorological stations were used for this study and covered into 5 regions of Thailand: 21 Stations in northern region, 16 stations in northeastern region, 9 stations in central region, 10 stations in eastern region and 17 stations in southern region (shown as the dot in Fig. 1). The average monthly maximum temperature data were collected at each of 73 meteorological stations over 30 year period, thus totaling 2,550 observations $(73 \times 30 \times 12)$ were analyzed in this study. Prior to analysis, all missing data were estimated. 


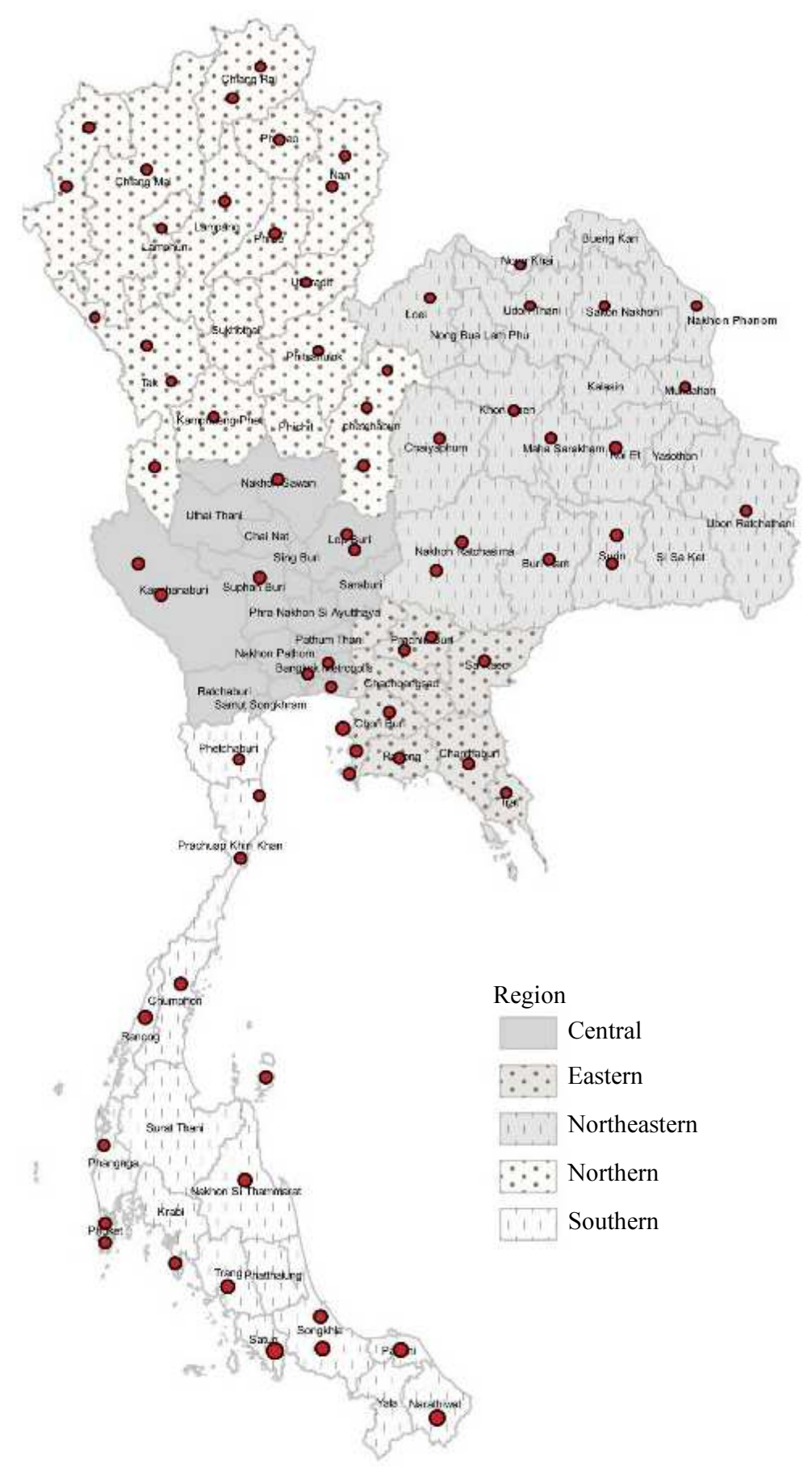

Fig. 1: The map of Thailand divided into 5 climatic regions

\section{Methods}

Let $y_{i t m}$ be the average monthly maximum temperature data collected at the $i^{\text {th }}$ station, in the $t^{\text {th }}$ year and in the $m^{\text {th }}$ month, where $i=1,2, \ldots, 73, t=$ $1,2, \ldots, 30, m=1,2, \ldots, 12$. To study the characteristics of data, the observed time series data were assumed to be composed of additive or multiplicative combination of different components. The data $\left(y_{i t m}\right)$ were seasonally adjusted to remove variation in the average maximum temperature as follows:

$$
\begin{aligned}
& \text { For additive model; } x_{i t m}=y_{i t m}-S_{i m}+T_{i} \\
& \text { For multiplicative model; } x_{i t m}=\frac{y_{i t m}}{S_{i m}} \times T_{i}
\end{aligned}
$$


where, $S_{i m}=\frac{1}{30} \sum_{t=1}^{30} y_{i t m}$ is the mean of each month of the $i^{\text {th }}$ station and $T_{i}=\frac{1}{30 \times 12} \sum_{t=1}^{30} \sum_{m=1}^{12} y_{i t m}$ is the mean of the temperature of the $i^{\text {th }}$ station.

At any $i^{\text {th }}$ station, the dependencies among the seasonally adjusted average maximum temperature data $\left(x_{i t m}\right)$ were investigated by using Autocorrelation Function (ACF) and Partial Autocorrelation Function (PACF). Then a linear regression model of $x_{i t m}=x_{i r}$ was fitted to the seasonally and autocorrelation adjusted average maximum temperatures, the model took the following form:

$$
x_{i r}=b_{0 i}+b_{1 i} d_{i r}+\varepsilon_{i r} ; r=1,2, \ldots, t \times m=360
$$

where, $x_{i r}$ is the seasonally and autocorrelation adjusted average maximum temperatures from the $i^{\text {th }}$ station, $r^{\text {th }}$ month; $d_{i r}$ is the time elapsed in decades since 1986, centered at the middle of the period, that is, $d_{i r}=\frac{\left(r-\frac{n}{2}\right)}{120}, \mathrm{n}$ is the total observations in each station ( $\mathrm{n}=360) ; b_{0 i}$ is the average temperature in the $i^{\text {th }}$ station during the study period; $b_{1 i}$ is the rate of temperature increase or decrease per decade.

Autoregressive $(\mathrm{AR}(\mathrm{p}))$ or Autoregressive Moving Average (ARMA $(p, q))$ models were used to account for autocorrelations among the residual $\left(e_{i r}=x_{i r}-\hat{x}_{i r}\right)$ from the fitted linear models. Autocorrelations in the average monthly temperature in each station was removed. For example, the residuals $\left(Z_{i r}\right)$ from a second order AR $(\mathrm{AR}(2))$ model take the form:

$$
Z_{i r}=x_{i r}-\hat{a}_{1 i} x_{i(r-1)}-\hat{a}_{2 i} x_{i(r-2)} .
$$

The average value of $Z_{i r}$ in each region was taken, then simple linear regression model was fit to estimate temperature change for each region is:

$$
\bar{Z}_{j r}=b_{0 j}+b_{1 j} d_{j r}+v_{j r} ; j=1,2,3,4,5 ; r=1,2, \ldots, 360
$$

and the prediction equation is:

$$
\hat{\bar{Z}}_{j r}=\hat{b}_{0 j}+\hat{b}_{1 j} d_{j r}
$$

where, $\hat{b}_{0 i}, \hat{b}_{1 i}$ is least square estimators of $b_{0 i}$ and $b_{1 i}$ respectively.

All data analysis and graphical displays were performed using $R$ program (RDCT, 2008). Study diagrams as follows (Fig. 2):

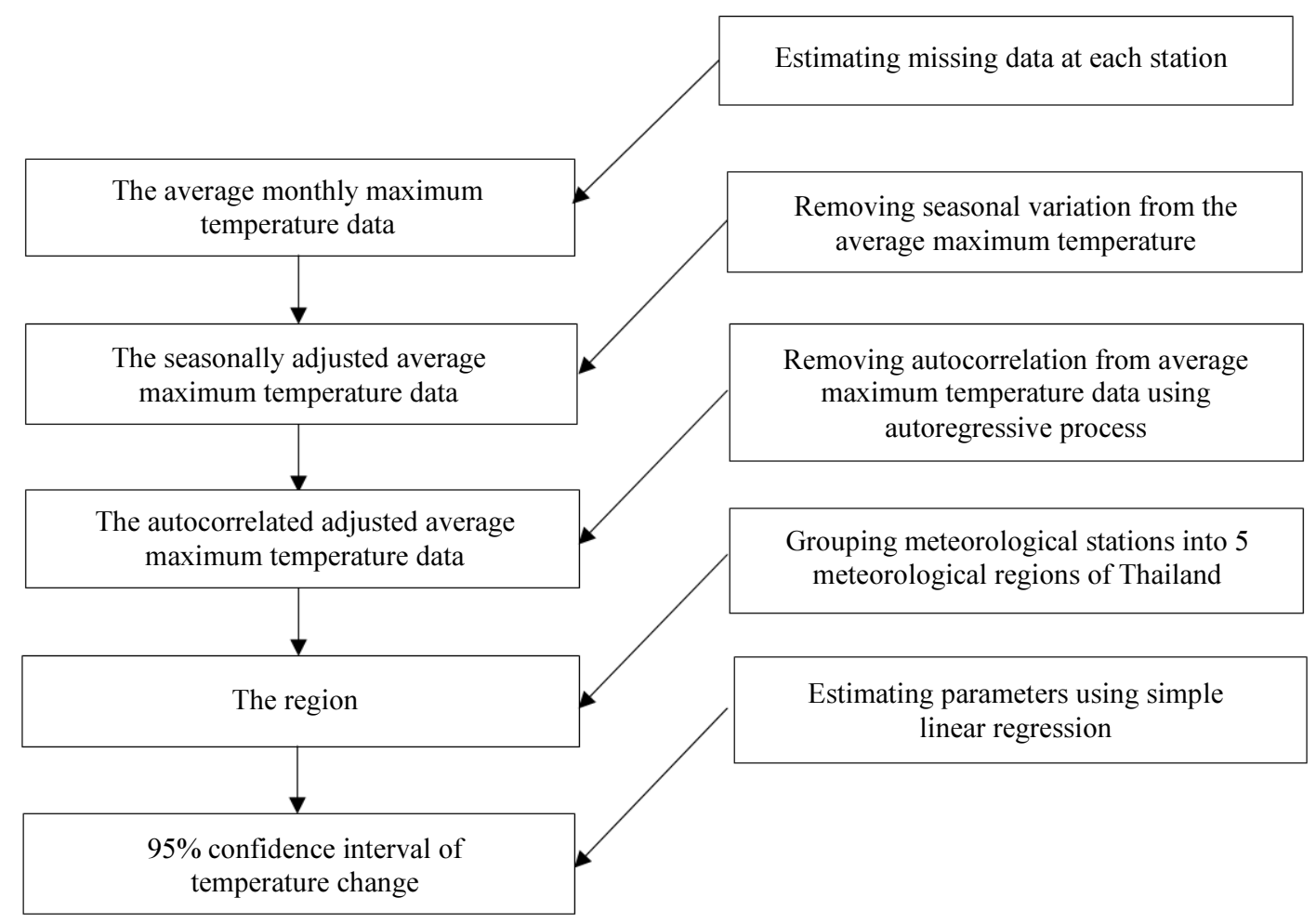

Fig. 2: Diagrams methods to analyze data 


\section{Results}

For illustration, Fig. 3 shows some results of investigating the additive and multiplicative pattern of maximum temperature data for the selected stations.

There are 30 stations which have additive pattern of different components, such as Nong Khai, Hua Hin and Songkhla station, while 43 stations have multiplicative pattern, such as Chiang Mai, Uttaradit, Phuket Airport station (Fig. 3 for examples). The data were seasonally adjusted to remove variation, according to the time series plot of investigating the additive and multiplicative pattern of maximum temperatures and then by using Autocorrelation Function (ACF) and Partial Autocorrelation Function (PACF) to investigate, the dependencies among the seasonally adjusted average maximum temperature data were investigated. For illustration, autocorrelation coefficients of monthly maximum temperature in station at Chiang Mai, Nong Khai and Hua Hin where represent as Northern, North East and Southern part of Thailand respectively were investigated (Table 1).

By statistical techniques, the autocorrelations were accounted. So, the Autoregressive $(\operatorname{AR}(p))$ or autoregressive moving average $(\operatorname{ARMA}(p, q))$ models were fitted to the residual from the linear regression models which the correlations in residuals from this fitted model are assumed to be stationary. We removed the seasonal effects and autoregressive effects from the monthly maximum temperature in each station in each region, for example stations as showed in Fig. 4. For the whole country, we found that there is only 1 station with no autocorrelation, 39 stations with eliminated the autocorrelations by using the AR(1) model, 16 stations with eliminated the autocorrelations by using the AR(2) model and 17 stations with eliminated the autocorrelations by using the ARMA model $(1,1)$.

As a result, maximum temperature data remained only trends component in it. The adjusted data of meteorological stations will be grouped into 5 meteorological regions of Thailand. The results of analysis according to the 5 meteorological regions and for the whole country of Thailand by using simple linear regression were shown as in Fig. 5.

Table 2 showed the $95 \%$ confidence intervals of temperature change in each region and the whole country of Thailand. The results indicated that, over the last 10 years, the northern, central, eastern, northeastern and southern regions had trends of the maximum surface temperature, increasing by $0.164^{\circ} \mathrm{C}$ $0.137^{\circ} \mathrm{C} 0.127^{\circ} \mathrm{C} 0.194^{\circ} \mathrm{C} 0.068^{\circ} \mathrm{C}$, respectively. For the whole country, the maximum surface temperature increasing by $0.141^{\circ} \mathrm{C}$ in the last 10 years at a significant level of 0.05 .

Forecasting values for the next 10 years, 2025, we found that the northern, central, eastern, northeastern and southern regions of Thailand trends to have the average maximum temperature at $36.2103^{\circ} \mathrm{C} \quad 36.4385^{\circ} \mathrm{C}$ $35.2605^{\circ} \mathrm{C} 36.5408^{\circ} \mathrm{C} 34.5304^{\circ} \mathrm{C}$ respectively. For the whole country, Thailand trends to have the average maximum temperature at $35.8041^{\circ} \mathrm{C}$ at a significant level of 0.05 as Table 3 .

Table 1: Autocorrelation coefficient of monthly maximum temperature of some illustration examples

\begin{tabular}{lllllllllr}
\hline Lag & Chi-square & Df & Pr & Autocorrelations & & & \\
\hline Chiang Mai Station & & & & & & & & \\
6 & 190.91 & 6 & $<0.001$ & 0.500 & 0.399 & 0.265 & 0.146 & 0.118 & 0.100 \\
12 & 204.45 & 12 & $<0.001$ & -0.034 & 0.040 & 0.046 & 0.067 & 0.098 & 0.132 \\
18 & 216.46 & 18 & $<0.001$ & 0.107 & 0.100 & 0.036 & 0.023 & -0.037 & -0.085 \\
24 & 219.08 & 24 & $<0.001$ & -0.039 & -0.020 & 0.017 & 0.038 & -0.015 & -0.054 \\
Nong Khai Station & & & & & & & & & \\
Lag & Chi-square & Df & Pr & Autocorrelations & & & \\
6 & 52.29 & 6 & $<0.001$ & 0.296 & 0.164 & 0.126 & 0.048 & 0.082 & 0.063 \\
12 & 61.20 & 12 & $<0.001$ & 0.071 & 0.114 & 0.005 & 0.060 & -0.002 & 0.049 \\
18 & 69.20 & 18 & $<0.001$ & -0.028 & -0.070 & 0.009 & -0.046 & -0.101 & -0.054 \\
24 & 77.29 & 24 & $<0.001$ & -0.059 & -0.043 & -0.087 & -0.083 & -0.034 & -0.014 \\
Hua Hin Station & & & & & & & & & \\
Lag & Chi-square & Df & Pr & Autocorrelations & & & \\
6 & 207.04 & 6 & $<0.001$ & 0.439 & 0.300 & 0.290 & 0.279 & 0.279 & 0.213 \\
12 & 269.95 & 12 & $<0.001$ & 0.208 & 0.164 & 0.162 & 0.160 & 0.194 & 0.101 \\
18 & 297.21 & 18 & $<0.001$ & 0.115 & 0.099 & 0.120 & 0.072 & 0.088 & 0.146 \\
24 & 312.59 & 24 & $<0.001$ & 0.070 & 0.042 & 0.019 & 0.098 & 0.126 & 0.085 \\
\hline
\end{tabular}


Table 2: Linear regression coefficient of the revised average monthly maximum temperature data in 5 meteorological regions and the whole country of Thailand

\begin{tabular}{llll}
\hline Area & $\mathrm{b}_{1}$ & Lower $(2.5 \%)$ & Upper (97.5\%) \\
\hline Thailand & 0.1407 & 0.0694 & 0.2119 \\
Northern & 0.1635 & 0.0672 & 0.2598 \\
Central & 0.1368 & 0.0548 & 0.2188 \\
Eastern & 0.1268 & 0.0643 & 0.1894 \\
Northeastern & 0.1935 & 0.0834 & 0.3036 \\
Southern & 0.0676 & 0.0170 & 0.1182 \\
\hline
\end{tabular}

Table 3: The forecasting values for 2025 of the revised average of monthly maximum temperatures in 5 meteorological regions and the whole country of Thailand

\begin{tabular}{llll}
\hline Area & Point.Forecast & Lower (2.5\%) & Upper (97.5\%) \\
\hline Thailand & 35.8041 & 34.6180 & 36.9901 \\
Northern & 36.2103 & 34.6078 & 37.8127 \\
Central & 36.4385 & 35.0738 & 37.8031 \\
Eastern & 35.2605 & 34.2203 & 36.3007 \\
Northeastern & 36.5408 & 34.7096 & 38.3720 \\
Southern & 34.5304 & 33.6887 & 35.3721 \\
\hline
\end{tabular}

Maximum temperature of Chiang Mai Check model

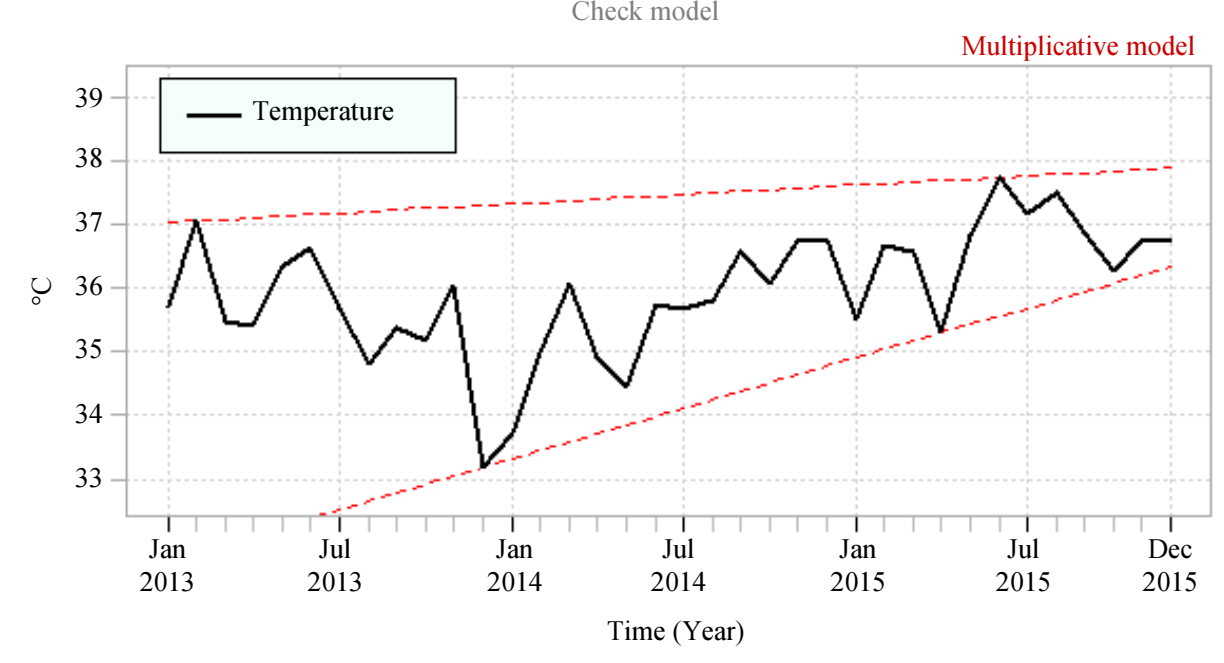

Maximum temperature of Uttaradit

Check model

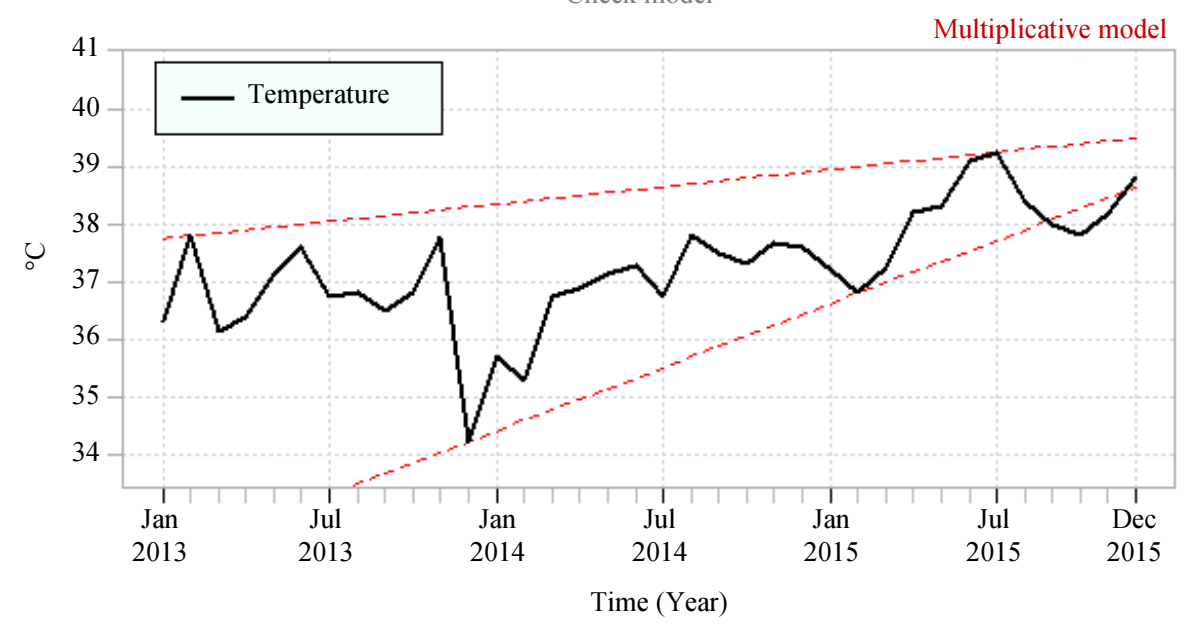



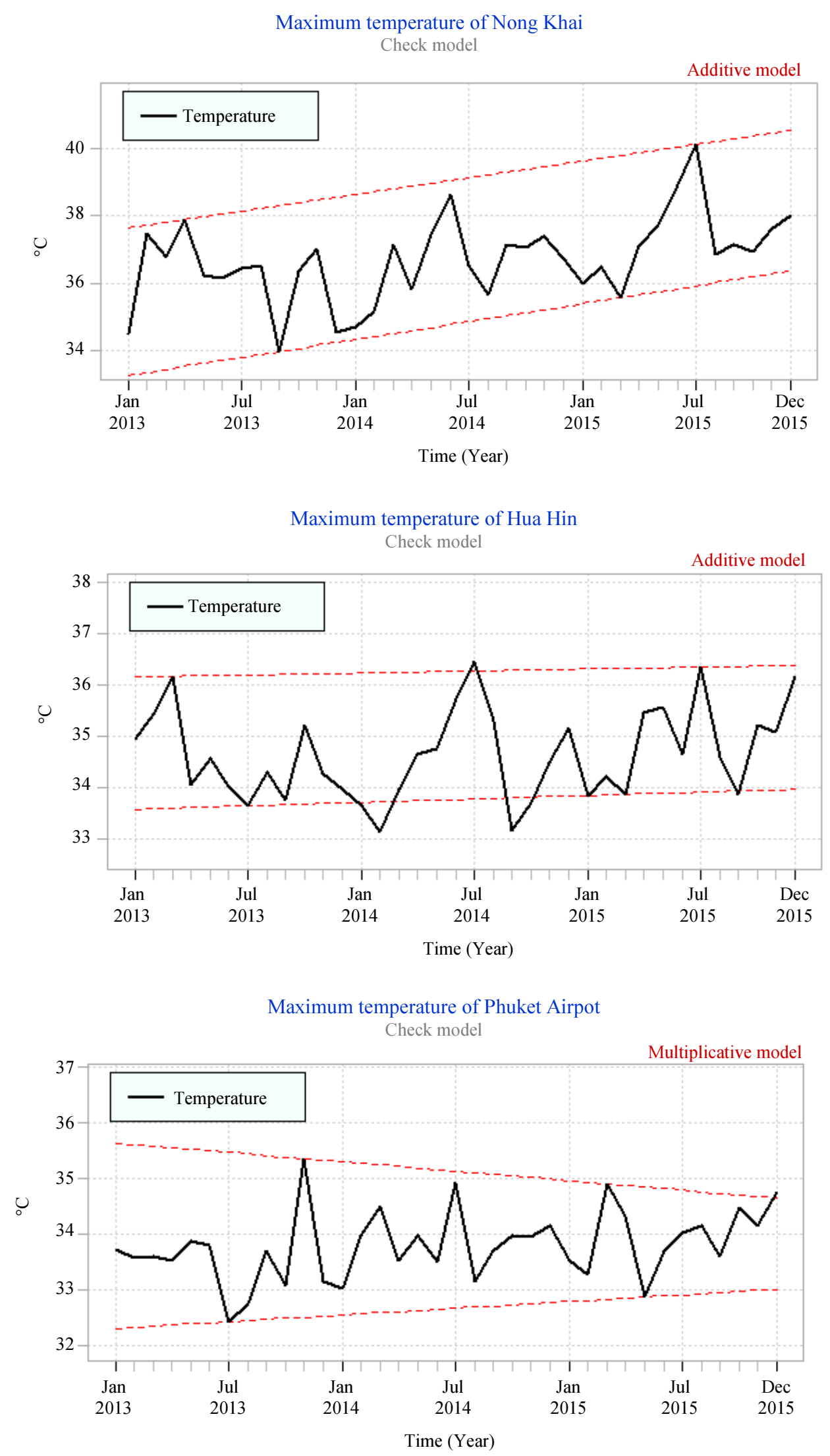


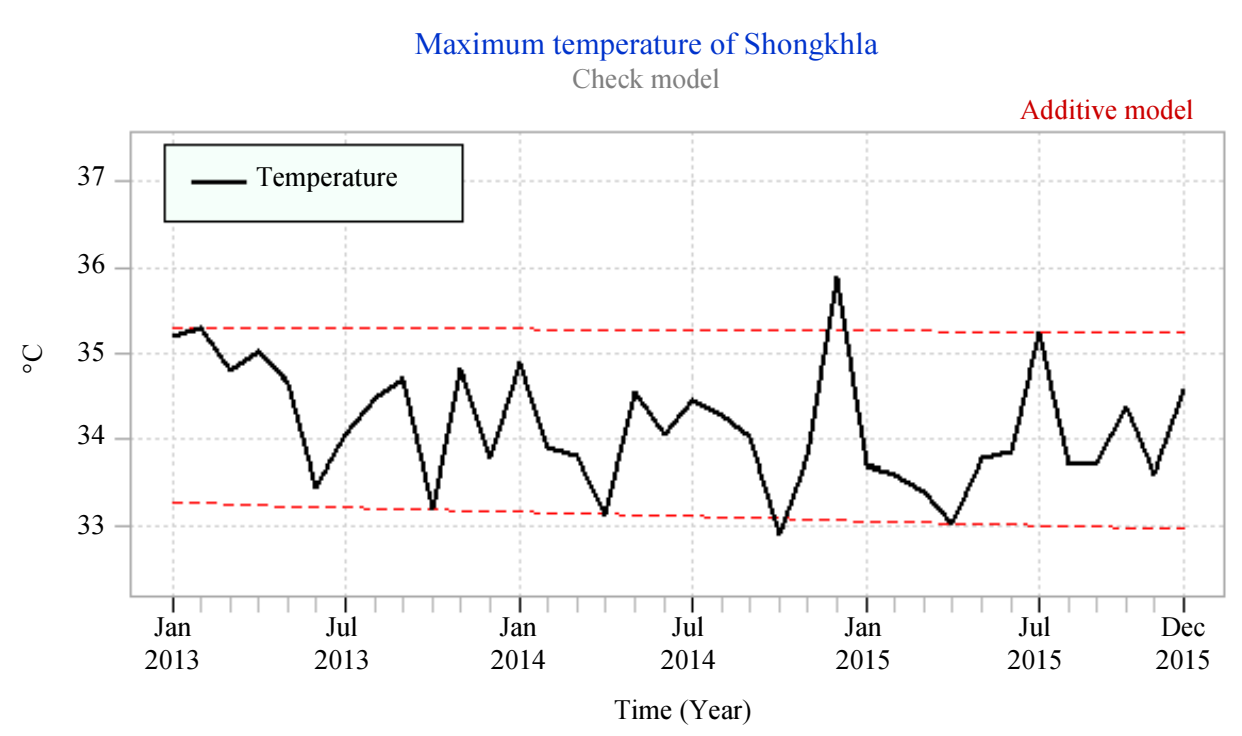

Fig. 3: Additive and multiplicative pattern of maximum temperatures for the selected stations
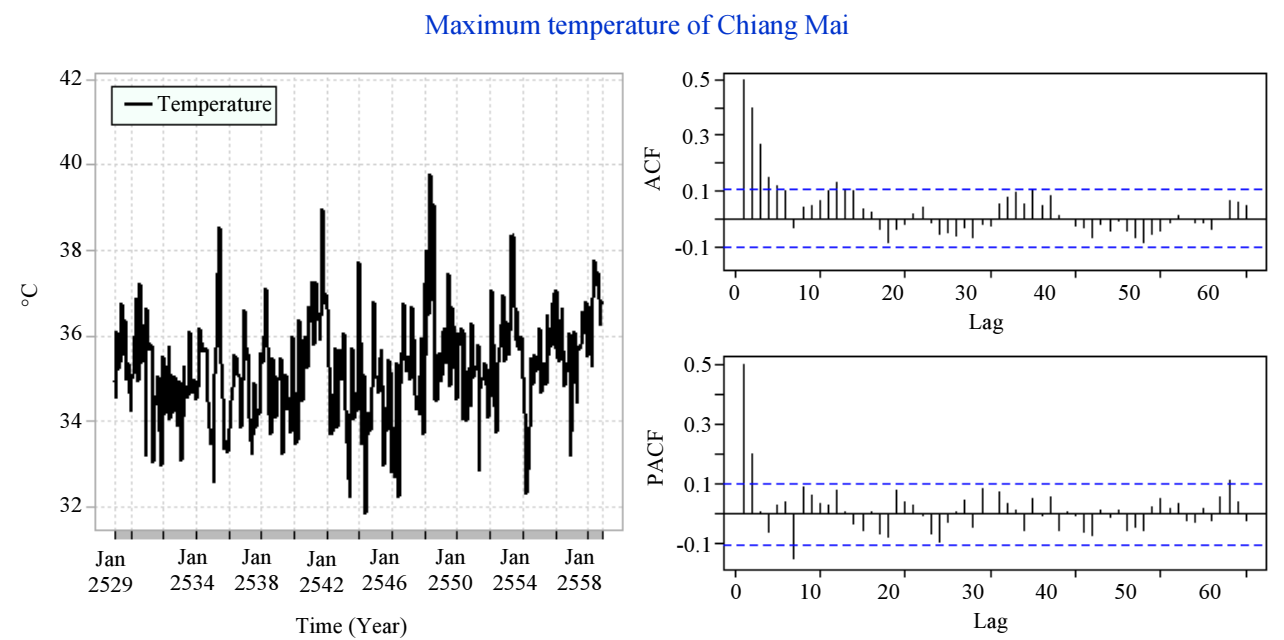

Maximum temperature of Chiang Mai (Remove seasonal)
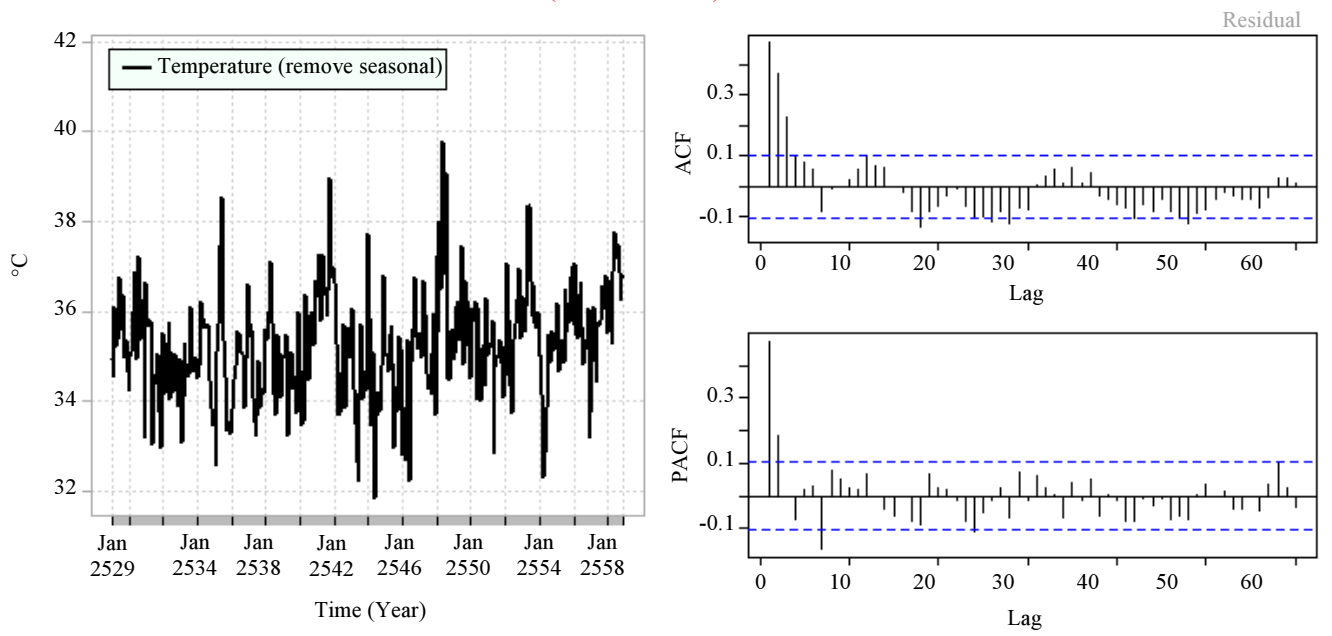

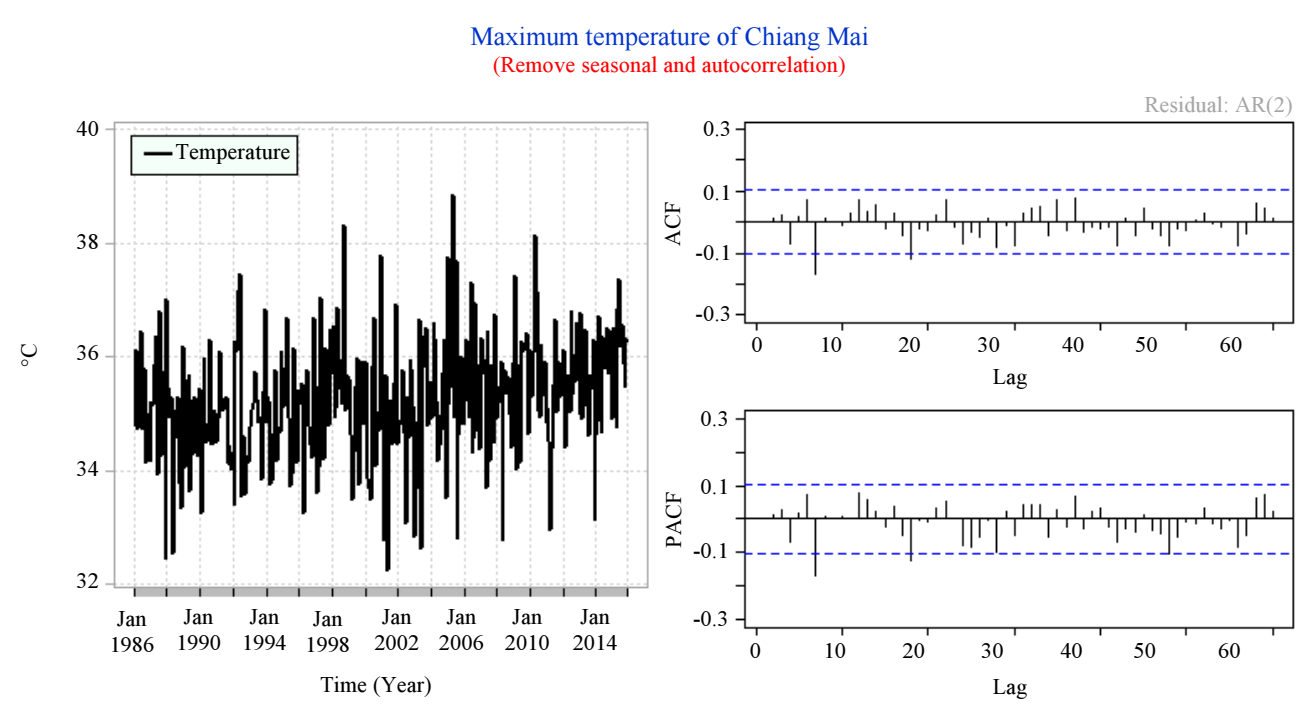

Maximum temperature of Nong Khai
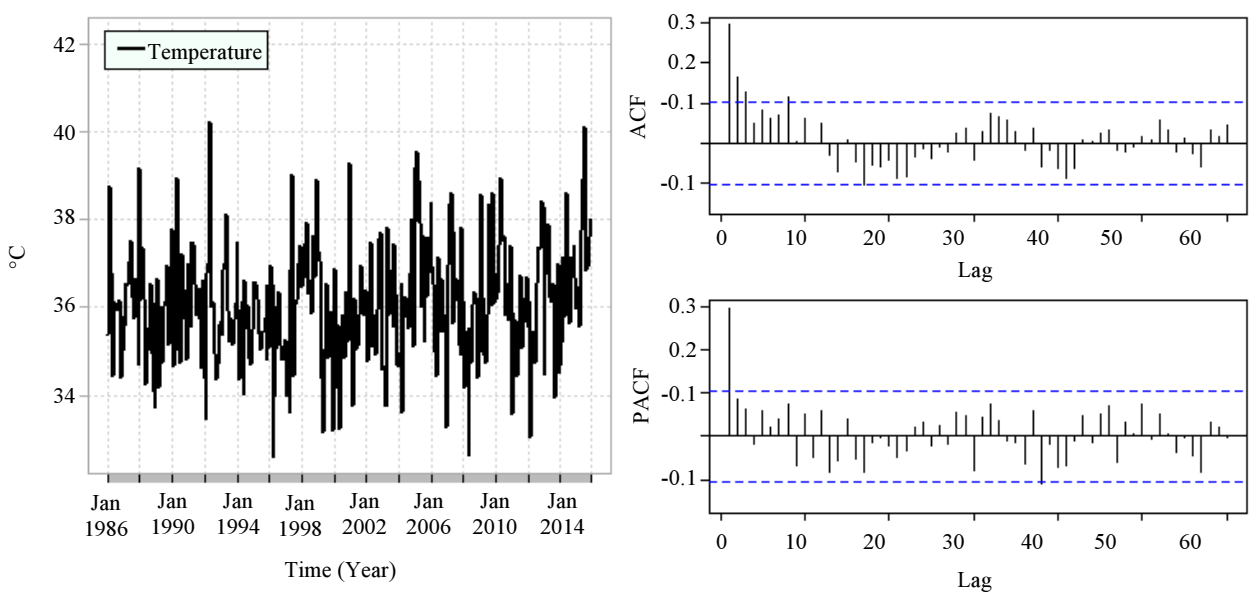

Maximum temperature of Nong Khai (Remove seasonal)
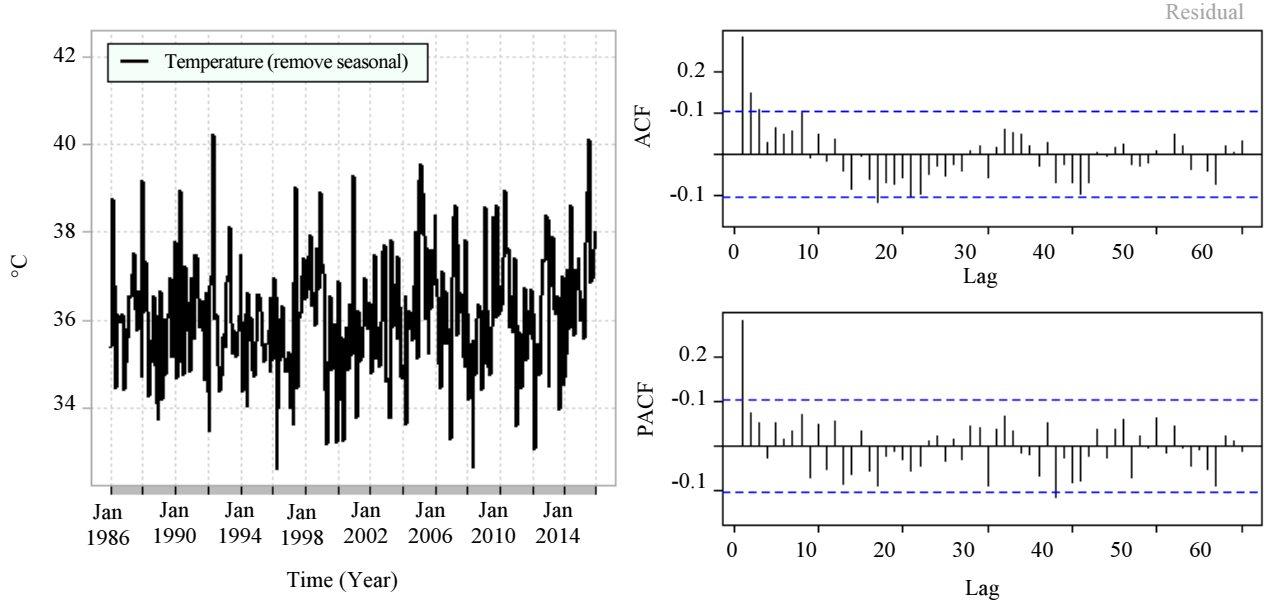
Maximum temperature of Nong Khai

(Remove seasonal and autocorrelation)
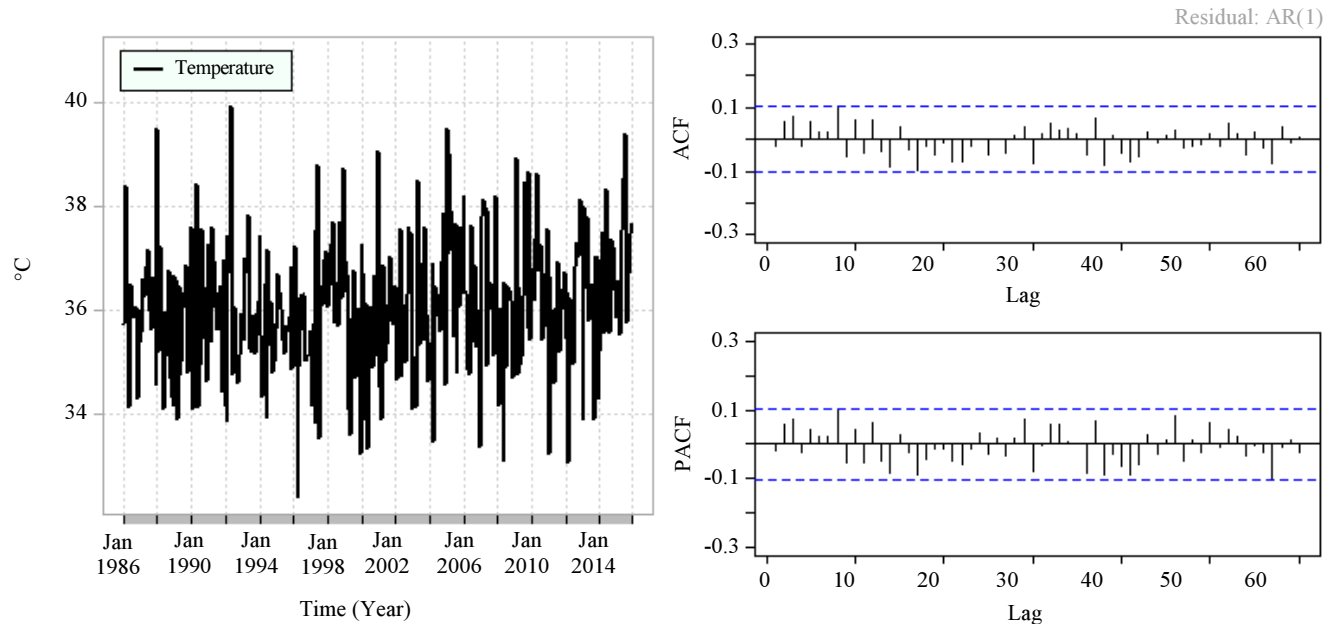

Maximum temperature of Hua Hin
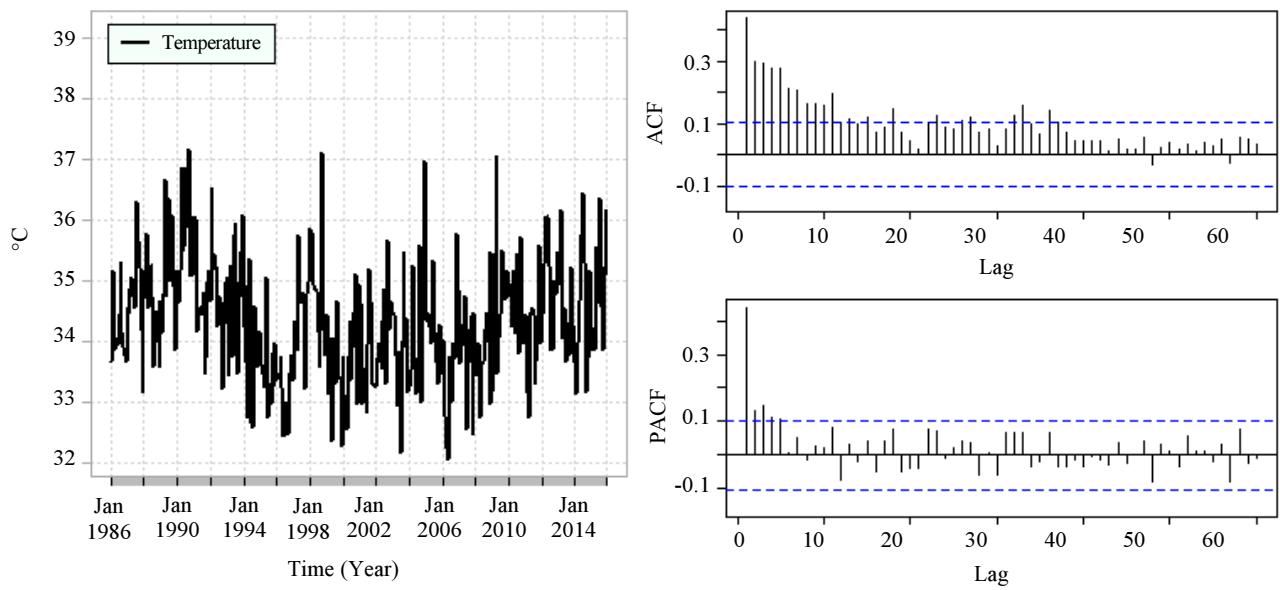

Maximum temperature of Hua Han (Remove seasonal)
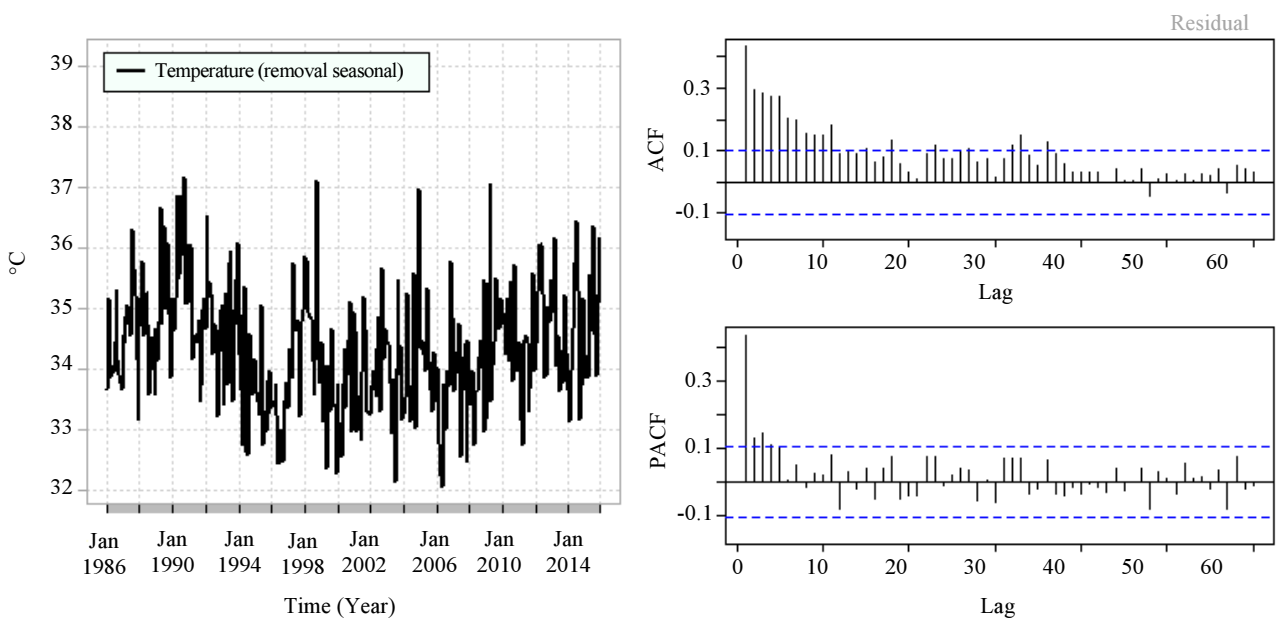

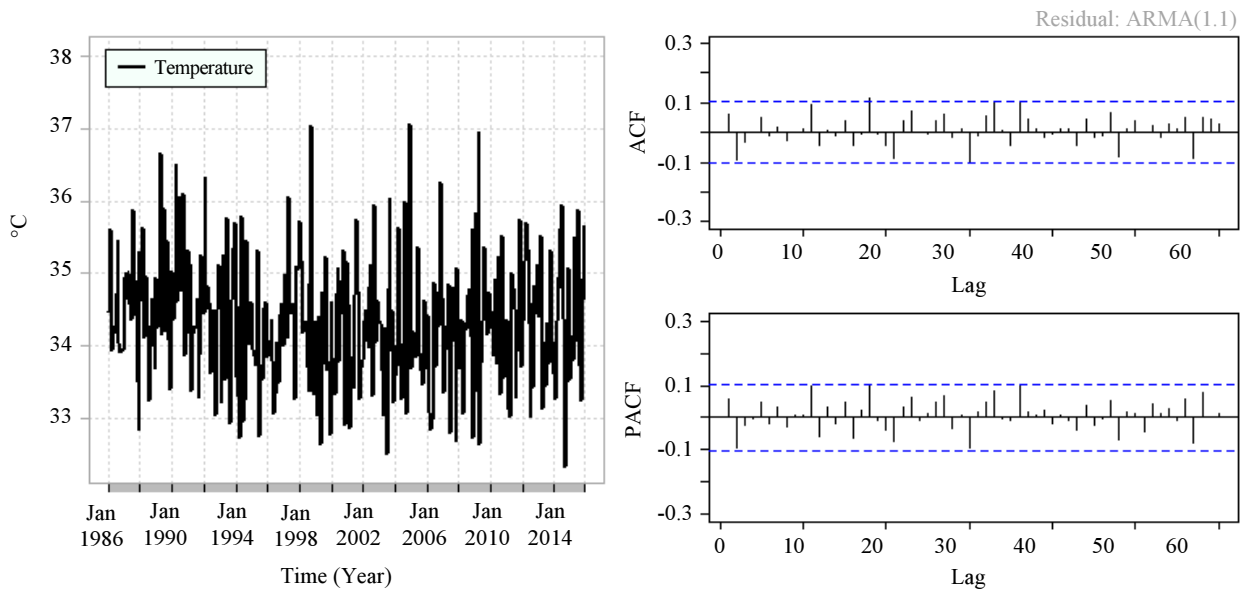

Fig. 4: The eliminated seasonal effects and autoregressive effects of the monthly maximum temperature data for some illustrated stations
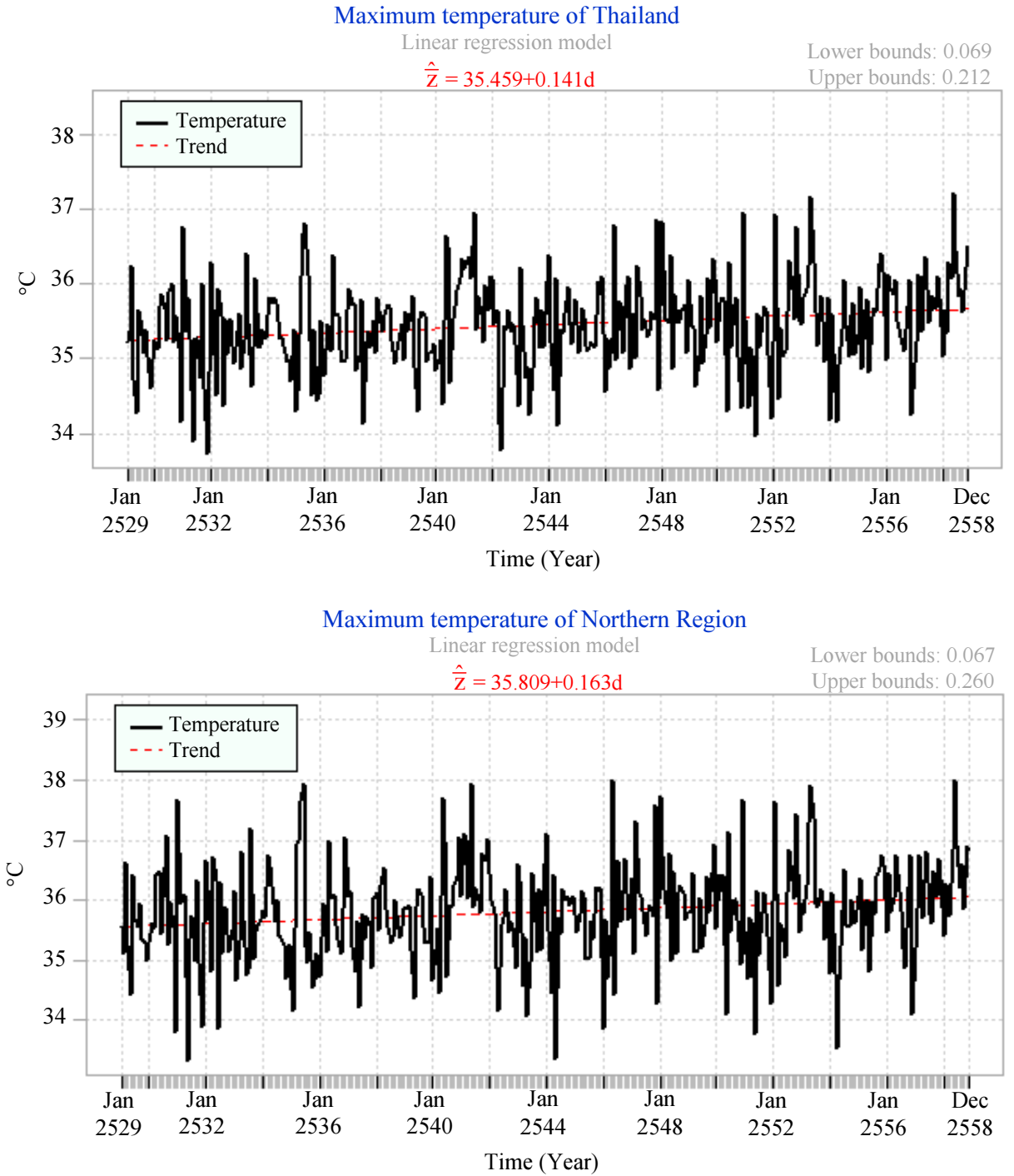

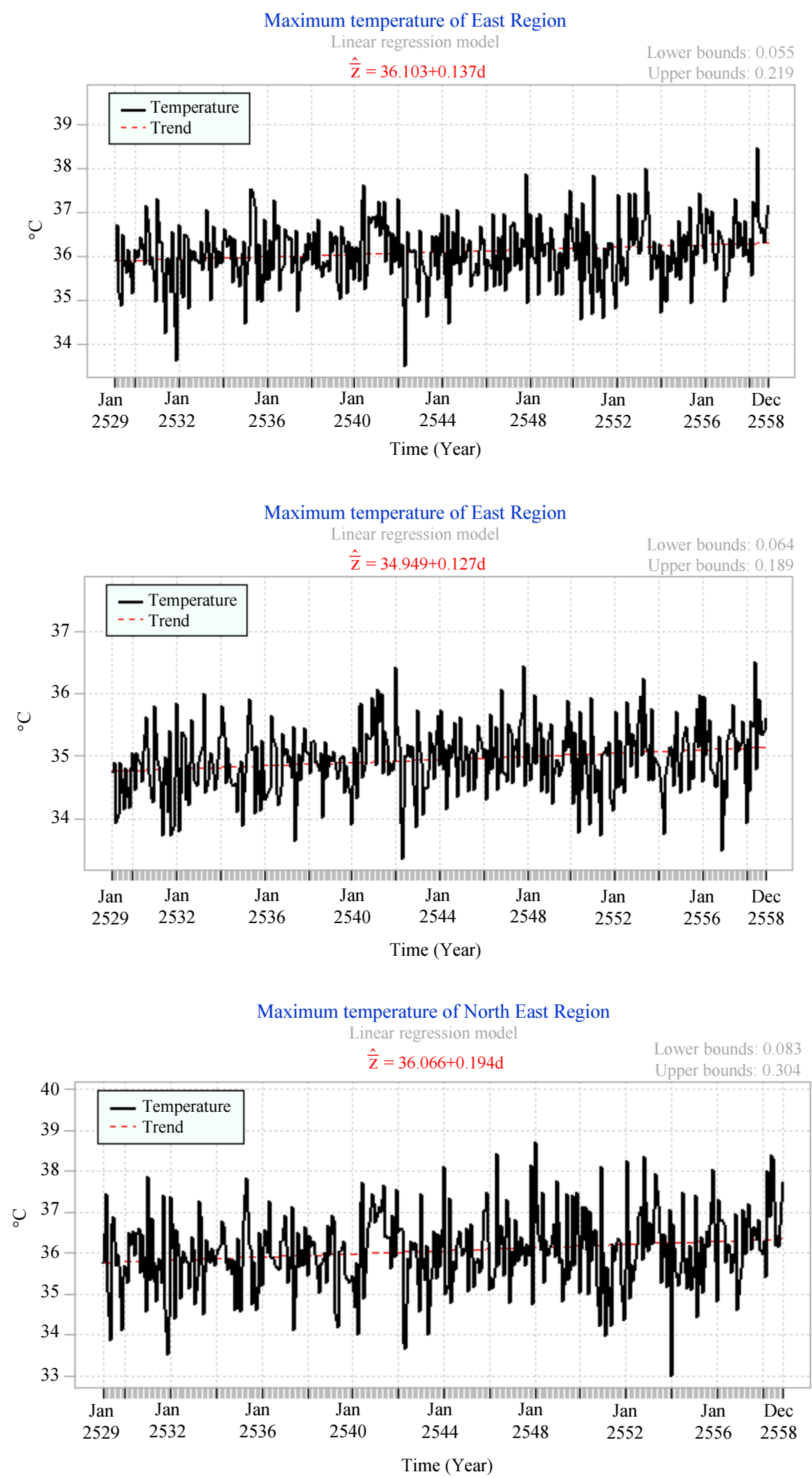


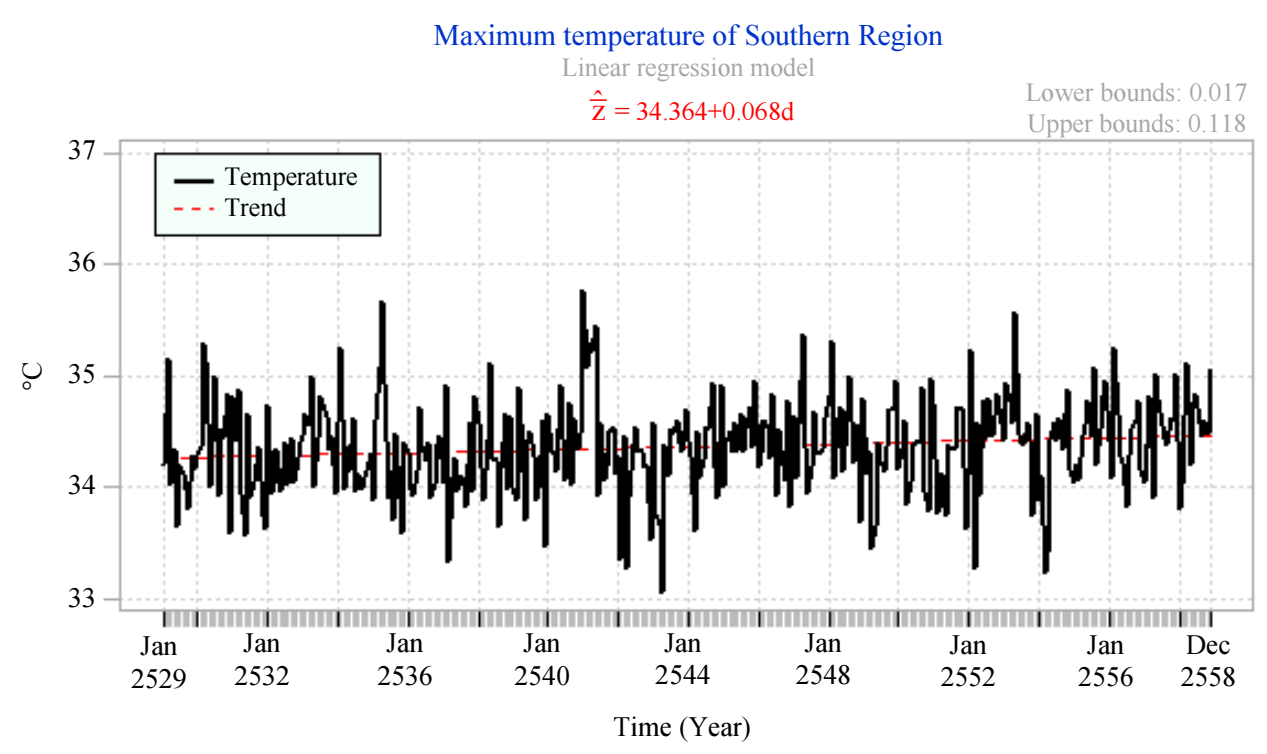

Fig. 5: The simple linear regression equations of the revised average monthly maximum temperature data in 5 meteorological regions and the whole country of Thailand

\section{Discussion}

The trends and patterns of maximum temperature changing data of monthly surface in Thailand during the 30 year-period from 1986 to 2015 were investigated by using the temperature data of 73 complete record meteorological stations that distributed in 5 regions of Thailand. In this study, the observed time series data were assumed to be composed of additive or multiplicative combination of seasonal and trend variation. The seasonal variation and autocorrelation have been removed from temperature data for each station. To study trend in average monthly maximum temperature data, a simple linear regression model was then used to fit the adjusted monthly maximum temperature in each region and the whole country of Thailand.

The result of forecasting that the average monthly maximum temperature significantly increased by range from $0.068-0.194^{\circ} \mathrm{C}$ per decade in each part of Thailand: northern $\left(0.164^{\circ} \mathrm{C}\right)$, central $\left(0.137^{\circ} \mathrm{C}\right)$, eastern $\left(0.127^{\circ} \mathrm{C}\right)$, northeastern $\left(0.194^{\circ} \mathrm{C}\right)$ and southern $\left(0.068^{\circ} \mathrm{C}\right)$ and increased by $0.141^{\circ} \mathrm{C}$ for the whole country. These findings consistent with previous reports that state a positive shift in the temperature distribution in many parts of the world. The temperature change might be resulting from e.g., significant changes in rainfall patterns and rainfall extreme events over the last four-five decades, significant decrease in frequency of tropical cyclones entering Thailand, significant rise in sea level in the seas around Thailand at higher rates than the global average (Limsakul et al., 2019).

The results also indicated that the highest increasing rate was found in northeastern region and the lowest increasing rate was found in southern regions of Thailand.
These findings revealed the evidence of the geographical pattern in maximum temperature distribution in different regions. The local variability of temperature change might be due to the effect of different natural (frequency and intensity of extreme events such as number of cold or warm days and nights, the annual occurrence of cold spells and warm spells are inequality in each region) (Limsakul et al., 2011) and human factors (land use and urban activities). The climate of Thailand is under the influence of monsoon winds of seasonal character i.e., southwest monsoon and northeast monsoon. In the Southern Part, this monsoon causes mild weather and abundant rain along the eastern coast of the part, while it causes dry spell over upper Thailand.

\section{Conclusion}

The average monthly maximum temperature were found to have significantly increased in all part of Thailand (by range from $0.068-0.194^{\circ} \mathrm{C}$ per decade). The result revealed the evidence of the geographical pattern in maximum temperature distribution in different regions. This methodological approach used in the present study may be useful to other researchers who face similar characteristics data and objectives in different areas of this globe can apply this technique for their works.

\section{Acknowledgement}

This research was supported by Chiang Mai University.

\section{Funding}

This study did not receive any funding. 


\section{Author Contributions}

Manachai Rodchuen: Contributed to the study conception and design, material preparation and data collection, conducted the statistical analyses, read and approved the final manuscript.

Samruam Chongcharoen: Contributed to the study conception and design, material preparation and data collection, read and approved the final manuscript.

Walaithip Bunyatisai: Contributed to the study conception and design, conducted the statistical analyses, wrote the first draft of the manuscript, read and approved the final manuscript.

\section{Ethics}

This article is original and contains unpublished material. The corresponding author confirms that all of the other authors have read and approved the manuscript and no ethical issues involved.

\section{References}

ADB, 2009. The economics of climate change in Southeast Asia: A regional review. Asian Development Bank, Manila, Philippines.

CCSP, 2008. Weather and Climate Extremes in a Changing Climate. In: Regions of Focus: North America, Hawaii, Caribbean and U.S. Pacific Islands. A Report by the U.S. Climate Change Science Program and the Subcommittee on Global Change Research, Karl, T.R., G.A. Meehl, C.D. Miller, S.J. Hassol and A.M. Waple et al., (Eds.), Department of Commerce, NOAA's National Climatic Data Center, Washington, D.C., USA.

Chooprateep, S. and N. McNeil, 2014. Temperature changes in southeast Asia: 1973-2008. CMU J. Nat. Sci., 13: 105-116. DOI: 10.12982/cmujns.2014.0025

Collins, D.A., P.M. Della-Marta, N. Plummer and B.C. Trewin, 2000. Trends in annual frequencies of extreme temperature events in Australia. Aust. Met. Mag, 49: 277-292.

Collins, J.M., 2011. Temperature variability over Africa. J. Clim., 24: 3649-3666. DOI: $10.1175 / 2011$ jcli3753.1

Dhimal, M., B. Ahrens and U. Kuch, 2015. Climate change and spatiotemporal distributions of vectorborne diseases in Nepal-A systematic synthesis of literature. PLoS One, 10: e0129869-e0129869. DOI: 10.1371/JOURNAL.PONE.0129869

Eckstein, D., M.L. Hutfils and M. Winges, 2018. Global Climate Risk Index. 1st Edn., Germanwatch Nord-Süd Initiative E.V., ISBN-10: 3943704602.
Griffiths, G.M., L.E. Chambers, M.R. Haylock, M.J. Manton and N. Nicholls et al., 2005. Change in mean temperature as a predictor of extreme temperature change in the Asia-Pacific region. J. Climatol., 25: 1301-1330. DOI: 10.1002/joc.1194

Gupha-Sapir, D., D. Hargitt and P. Hoyois, 2004. Thirty years of natural disasters 1974-2003: The number. Center for Research on the Epidemiology of Disasters, UCL Presses, Universitaires De Louvain

Hansen, J., M. Sato, R. Ruedy, K. Lo and D.W. Lea et al., 2006. Global temperature change. Proc. Natl. Acad. Sci., 103: 14288-14293. DOI: 10.1073/PNAS.0606291103

Houghton, R.W. and Y.M. Tourre, 1992. Characteristics of low-frequency sea surface temperature fluctuations in the tropical Atlantic. J. Clim., 5: 765-772.

DOI:

$10.1175 / 1520-$ 0442(1992)005<0765:COLFSS $>2.0$. CO; 2

Hughes, G.L., S.S. Rao and T.S. Rao, 2006. Statistical analysis and time-series models for minimum/maximum temperatures in the antarctic peninsula. Proc. Res. Soc. Ser A, 463: 241-259. DOI: $10.1098 /$ rspa.2006.1766

Hughes, L., 2003. Climate change and Australia: Trends, projections and impacts. Aust. Ecol., 28: 423-443. DOI: 10.1046/J.1442-9993.2003.01300.X

IPCC, 2001. Climate change: The Scientific Basis. In: Contribution of Working Group I to the Third Assessment Report of the Intergovernmental Panel on Climate Change, Houghton, J.T., Y. Ding, D.J. Griggs, M. Noguer and P.J. van der Linden et al. (Eds.), Cambridge University Press, Cambridge, USA.

IPCC, 2007. Climate change 2007: The physical science Basis. Proceedings of the Contribution of Working Group I to the Fourth Assessment Report of the Intergovernmental Panel on Climate Change: Frequently Asked, Cambridge University Press.

IPCC, 2012. Managing the Risks of Extreme Events and Disasters to Advance Climate Change Adaptation. In: A Special Report of Working Groups I and II of the Intergovernmental Panel on Climate Change, Field, C.B., V. Barros, T.F. Stocker, D. Qin and D.J. Dokken et al. (Eds.), Cambridge University Press, Cambridge, United Kingdom and New York, New York, USA.

Jaglom, W.S., J.R. McFarland, M.F. Colley, C.B. Mack and B. Venkatesh et al., 2014. Assessment of projected temperature impacts from climate change on the U.S. electric power sector using the integrated planning model. Ene. Policy, 73: 524-539. DOI: $10.1016 /$ j.enpol.2014.04.032

James, R. and R. Washington, 2013 Changes in African temperature and precipitation associated with degrees of global warming. Climatic Change, 117: 859-872. DOI: $10.1007 / \mathrm{s} 10584-012-0581-7$ 
Jiang, N., K. Cheung, K. Luo, P.J. Beggs and W. Zhou, 2012. On two different objective procedures for classifying synoptic wether types over east Australia. Int. J. Climatol., 32: 1475-1494. DOI: $10.1002 /$ joc. 2373

Johannessen, O.M., L. Bengtsson, M.W. Miles, S.I. Kuzmina and V.A. Semenov et al., 2004. Arctic climate change: Observe and modeled temperature and sea-ice variability. Tellus, 56: 328-341. DOI: 10.1111/J.1600-0870.2004.00060.X

Jones, P.D., M. New, D.E. Parker, S. Martin and I.G. Rijor, 1999. Surface air temperature and its changes over the past 150 years. Rev. Geophys., 37: 173-199. DOI: $10.1029 / 1999 \mathrm{rg} 900002$

Klein Tank, A.M.G., T.C. Peterson, D.A. Quadir, S. Dorji and X. Zou et al., 2006. Changes in daily temperature and precipitation extremes in central and south Asia. J. Geophys. Res. Atmos., 111: D16105-D16105. DOI: 10.1029/2005jd006316

Lean, J.L. and D.H. Rind, 2009. How will earth's surface temperature change in future decades? Geophys. Res. Lett., 36: L5708-L5708.

DOI: $10.1029 / 2009 \mathrm{gl} 038932$

Li, Z.L., B.H. Tang, H. Wu, H. Ren and G. Yan et al., 2013. Satellite-derived land surface temperature: Current status and perspectives. Remote Sens. Environ., 131: 14-37.

DOI: $10.1016 /$ J.RSE.2012.12.008

Limsakul, A., B. Kachenchart, P. Singhruck, S. Saramul and J. Santisirisomboon et al., 2019. Updated basis knowledge of climate change summarized from the first part of Thailand's second assessment report on climate change. Applied Environ. Res., 41: 1-12. DOI: 10.35762/AER.2019.41.2.1

Limsakul, A., S. Limjirakan, T. Sriburi and B. Suttamanuswong, 2011. Trends in temperature and its extremes in Thailand. TEEJ, 25: 9-16.

Mahlstein, I. and R. Knutti, 2009. Regional climate change patterns identified by cluster analysis. Clim. Dynam., 35: 587-600. DOI $10.1007 / \mathrm{s} 00382-009-0654-0$

Marks, D., 2011. Climate change and Thailand: Impact and response. Contemp. Southeast Asia, 33: 229-258. DOI: $10.1353 /$ csa.2011.0132

McAlpine, C.A., J. Syktus, R.C. Deo, P.J. Lawrence and H.A. McGowan et al., 2007. Modeling the impact of historical land cover change on Australia's regional climate. Geophys. Res. Lett., 34: L22711-L22711. DOI: 10.1029/2007g1031524

Mote, P.W., 2003. Trends in temperature and precipitation in the Pacific Northwest during the twentieth century. Northwest Sci., 77: 271-282.
Nemukula, M.M. and C. Sigauke, 2018. Modelling average maximum daily temperature using $r$ largest order statistics: An application to South African data. Jàmbá, 10: a467-a467. DOI: 10.4102/jamba.v10i1.467

Overpeck, J., K. Hughen, D. Hardy, R. Bradley and R. Case et al., 1997. Arctic environmental change of the last four centuries. Science, 278: 1251-1256. DOI: $10.1126 /$ science.278.5341.1251

Paniagua-Tineo, A., S. Salcedo-Sanz, C. Casanova-Mateo, E.G. Ortiz-Garcia and M.A. Cony et al., 2011. Prediction of daily maximum temperature using a support vector regression algorithm. Renew Energy, 36: 3054-3060. DOI: 10.1016/J.RENENE.2011.03.030

RDCT, 2008. A language and environment for statistical computing. $\mathrm{R}$ foundation for statistical computing: Vienna.

Rebetez, M. and M. Reinhard, 2007. Monthly air temperature trends in Switzerland 1901-2000 and 1975-2004. Theor. Applied Climatol., 91: 27-34. DOI: $10.1007 / \mathrm{s} 00704-007-0296-2$

Schlenker, W. and M.J. Roberts, 2009. Nonlinear temperature effects indicate severe damages to U.S. crop yields under climate change, Proc. National Acad. Sci. USA, 106: 15594-15598. DOI: 10.1073/PNAS.0906865106

Semenov, V.A., 2007. Structure of temperature variability in the high latitudes of the northern hemisphere. Atmo. Oceanic Phys., 43: 744-753. DOI: $10.1134 / \mathrm{S} 0001433807060023$

Sharma, I., P. Tongkumchum and A. Ueranantasun, 2018. Modeling of land surface temperatures to determine temperature patterns and detect their association with altitude in the Kathmandu valley of Nepal. CMU J. Nat. Sci., 17: 275-288. DOI: 10.12982/CMUJNS.2018.0020

Smith, J.B., S.H. Schneider, M. Oppenheimer, G.W. Yohe and W. Hare et al., 2009. Assessing dangerous climate change through an update of the Intergovernmental Panel on Climate Change (IPCC) "reasons for concern". Proc. National Acad. Sci. USA, 106: 4133-4137.

DOI: $10.1073 /$ PNAS.0812355106

The World Bank, 2009. Climate Change Impact and Adaptation Study for Bangkok Metropolitan Region: Final Report (Bangkok: World Bank, March 2009), pp: 10.

Tshiala, F.M., J.M. Olwoch and F.A. Engelbrecht, 2011. Analysis of temperature trends over Limpopo province. South Africa. JGG, 3: 13-21. DOI: $10.5539 /$ jgg.v3n1p13

Turner, J., J.C. King, T.A. Lachlan-Cope and P.D. Jones, 2002. Recent temperature trends in the Antarctic. Nature, 418: 291-292. DOI: 10.1038/418291b 
Turner, J., S.R. Colwell, G.J. Marshall, T.A. LachlanCope and A.M. Carleton, 2005. Antarctic climate change during the past 50 years. J. Climatol., 25: 279-294. DOI: $10.1002 / J O C .1130$

Wanishsakpong, W. and N. McNeil, 2016. Modelling of daily maximum temperatures over Australia from 1970 to 2012. Meteorol. Applied, 23: 115-122. DOI: $10.1002 /$ MET.1536

Wanishsakpong, W., K.A. Notodiputro and N. McNeil, 2016. Clustering and forecasting maximum temperature of Australia. Chiang Mai. J. Sci., 43: 904-914.
Weiss, J., 2009. The economics of climate change in Southeast Asia: A regional review. Asian Development Bank.

Xu, Z., Y. Jiang and G. Zhou, 2015. Response and adaptation of photosynthesis, respiration and antioxidant systems to elevated $\mathrm{CO}_{2}$ with environmental stress in plants. Front Plant Sci., 6: 701-701. DOI: 10.3389/fpls.2015.00701 